\title{
Quantitative structure-activity relationship of molecules constituent of different essential oils with antimycobacterial activity against Mycobacterium tuberculosis and Mycobacterium bovis
}

Sergio Andrade-Ochoa', Guadalupe Virginia Nevárez-Moorillón', Luvia E. Sánchez-Torres², Manuel Villanueva-García ${ }^{3}$, Blanca E. Sánchez-Ramírez', Luz María Rodríguez-Valdez and Blanca E. Rivera-Chavira ${ }^{1 *}$

\begin{abstract}
Background: Essential oils and their constituents are commonly known for their antibacterial, antifungal and antiparasitic activity, and there are also reports on the antimycobacterial properties, but more experimental data are needed for the description of the mechanism of action or structural (and molecular) properties related to the antimicrobial activity.

Methods: Twenty-five constituents of essential oils were evaluated against Mycobacterium tuberculosis H37Rv and Mycobacterium bovis AN5 by the Alamar Blue technique. Twenty compounds were modeled using in silico techniques descriptor generation and subsequent QSAR model building using genetic algorithms. The $p$-cymene, menthol, carvacrol and thymol were studied at the quantum mechanical level through the mapping of $\mathrm{HOMO}$ and LUMO orbitals. The cytotoxic activity against macrophages (J774A) was also evaluated for these four compounds using the Alamar Blue technique.
\end{abstract}

Results: All compounds tested showed to be active antimicrobials against M. tuberculosis. Carvacrol and thymol were the most active terpenes, with MIC values of 2.02 and $0.78 \mu \mathrm{g} / \mathrm{mL}$ respectively. Cinnamaldehyde and cinnamic acid were the most active phenylpropanes with MIC values of 3.12 and $8.16 \mu \mathrm{g} / \mathrm{mL}$ respectively. The QSAR models included the octanol-water partition (LogP) ratio as the molecular property that contributes the most to the antimycobacterial activity and the phenolic group $(\mathrm{nArOH})$ as the major structural element.

Conclusions: The description of the molecular properties and the structural characteristics responsible for antimycobacterial activity of the compounds tested, were used for the development of mathematical models that describe structure-activity relationship. The identification of molecular and structural descriptors provide insight into the mechanisms of action of the active molecules, and all this information can be used for the design of new structures that could be synthetized as potential new antimycobacterial agents.

Keywords: Essential oils, Terpenes, Phenylpropanoids, QSAR, Antimycobacterial activity

\footnotetext{
*Correspondence: bchavira@uach.mx

'Facultad de Ciencias Químicas, Universidad Autónoma de Chihuahua,

Circuito Universitario S/N. Campus Universitario II, Chihuahua 31125 Chih.,

México

Full list of author information is available at the end of the article
}

\section{Biomed Central}

(c) 2015 Andrade-Ochoa et al. Open Access This article is distributed under the terms of the Creative Commons Attribution 4.0 International License (http://creativecommons.org/licenses/by/4.0/), which permits unrestricted use, distribution, and reproduction in any medium, provided you give appropriate credit to the original author(s) and the source, provide a link to the Creative Commons license, and indicate if changes were made. The Creative Commons Public Domain Dedication waiver (http://creativecommons.org/publicdomain/zero/1.0/) applies to the data made available in this article, unless otherwise stated. 


\section{Background}

Tuberculosis is an infectious disease caused by Mycobacterium tuberculosis and other mycobacteria including Mycobacterium bovis. It is estimated that one-third of the world population is infected with $M$. tuberculosis and $5-10 \%$ of them will develop clinical symptoms [1]. The increase in the incidence of clinical tuberculosis is associated with increasing reports of new cases of multi drug resistant (MDR-TB) and extensively multidrug resistant (XDR-TB) strains [2]. The development of new drugs is critical for the future control of tuberculosis (TB) and a number of promising compounds are currently in the pipeline at various stages of drug discovery and clinical development [3]. Under this scenario, the design and synthesis of new anti-TB agents is essential for the development of novel pharmaceutical therapies.

Mexico possesses a vast geographic diversity, and has one of the richest flora on the planet [4]. In Mexico there are more than 4000 species of medicinal plants [5] and many of them produce essential oils, which are water-insoluble highly volatile extracts obtained by hydrodistillation. Their composition is complex and variable, but they are usually terpenes and/or phenylpropanes $[6,7]$. Due to their biological properties, including antimicrobial action, there is an increasing interest on terpenes and others molecules present in essential oils [8]; the biological activity varies depending on the structural configuration and functional groups of their constituent [9]. Regarding antimycobacterial activity of terpenes and phenylpropanes, several reports have shown that chain free monoterpenes have antimycobacterial activities of pharmaceutical importance [10-12]. These results have motivated the research on the molecular and reactivity properties of them, as the base for the design of new pharmacologically active compounds, that could use the molecules present in essential oils as building blocks.

Computer assisted prediction of the biological activity in relation to the chemical structure of a compound is a commonly used technique in drug discovery [13, 14]. Quantitative Structure-Activity Relationship (QSAR) studies have been widely used to understand the relationship between the chemical structure and biological activity of the molecules [15]. Our group has previously demonstrated that essential oils have antibacterial activity [16] and antimycobacterial activity against multi drug resistant strains [17]. On the basis of those results, the main objective of this study was to evaluate the antimycobacterial activity of 25 constituent molecules of essential oils in order to obtain a QSAR model that provide information on the elucidation of molecular properties of biological importance. In this context the models will help on the rational design and subsequent synthesis of new antimycobacterial compounds.
This study included the evaluation of the antimycobacterial activity of 25 compounds, terpenes and phenylporpanes that are constituent of different essential oils, against $M$. tuberculosis (H37Rv) and M. bovis (AN5) using the Alamar Blue technique. Isoniazid and rifampicin were used as controls. QSAR models were obtained using genetic algorithms techniques, with the inclusion of the four descriptors that had the higher contributions to the antimycobacterial activity.

\section{Methods}

\section{Bacterial cultures, growth conditions and bactericidal assays}

The bacterial strains used in this study were $\mathrm{H} 37 \mathrm{Rv}$ strain of $M$. tuberculosis and AN5 strain of M. bovis, both obtained from the National Institute of Medical Sciences and Nutrition "Salvador Zubirán" and INIFAP respectively. For the in vitro studies all strains were grown in Difco 7H9 Middlebrook liquid media (BD Biosciences, 271310) supplemented with $10 \%$ Middlebrook OADC Enrichment (VWR, 9000-614), $0.05 \%$ Tween (G-Biosciences, 786-519), and $0.2 \%$ Glycerol at $37{ }^{\circ} \mathrm{C}$. M. tuberculosis was grown on Difco Middlebrook $7 \mathrm{H} 11$ agar (BD Biosciences, 283810) supplemented with $1 \%$ Asparagine. Isoniazid (Sigma, I3377) and rifampicin (Sigma, R3501) were used as controls. The Minimum Inhibitory Concentration (MIC) of 25 major components of different essential oils was evaluated on the H37Rv strain of M. tuberculosis and AN5 M. bovis strain by the Alamar Blue technique $[18,19]$. A growth control containing no antimicrobial compounds and a sterile control were also prepared on each plate. Sterile water was added to all perimeter wells to avoid evaporation during the incubation. The plate was covered, sealed in plastic bags and incubated at $37{ }^{\circ} \mathrm{C}$. After 7 days incubation, $30 \mu \mathrm{L}$ of alamar blue solution was added to each well, and the plate was re-incubated overnight. A change in color from blue (oxidized state) to pink (reduced) indicated the growth of mycobacteria because of the change of color due to respiration of active cells, and the MIC was defined as the lowest concentration of drug that prevented this change in color. Each reaction was carried out in triplicates. Pure chemical compounds used in this study can be found in different essential oils as major components including anise ( $p$-anisaldehyde, $t$-anethole), bay (myrcene), blackcurrant (3-carene), camphor (camphor) caraway $((+)$ carvone), cinnamon (cinnamic acid, cinnamaldehyde), citronella ( $\beta$-citronellol), clove $(\beta$-cariophylene, eugenol), cumin ( $p$-cymene, cuminaldehyde), eucalyptus (eucalyptol), geranium (geraniol), holly oak (sabinene), lime $((+)$ limonene), mint (menthol), oregano (aarvacrol, thymol), tarragon (estragole), or they can be found in essential oils of plants from the Pinaceae family ( $\beta$-pinene), of the Lamiaceae family (linalool) or present in 
several essential oils ( $\alpha$-terpinene, terpinolene). The evaluated compounds (terpenes and phenylpropanes) were acquired through the distributor Sigma-Aldrich (St. Louis, MI, USA) and their chemical structures are shown in Fig. 1.

Cell lines, growth conditions and cytotoxic activity assays The J774A mouse monocyte macrophage cell line was grown in RPMI medium (Sigma, R0883) supplemented with $10 \%$ heat inactivated fetal bovine serum (FBS, Sigma-Aldrich), $1 \%$ MEM-NEAA medium (Gibco, 11140-050) and a mixture of penicillin-streptomycin to
$1 \%$. The cell culture was maintained at $37{ }^{\circ} \mathrm{C}$ with a partial atmosphere of $5 \% \mathrm{CO}_{2}$, the evaluations were carried out when 80-90\% confluence was reached.

In a 96 well plate 50,000 cells per well were deposited in a final volume of $100 \mu \mathrm{L}$, and incubated for $24 \mathrm{~h}$ at $37{ }^{\circ} \mathrm{C}$ in partial $\mathrm{CO}_{2}$ atmosphere to promote cell adhesion for an approximate $80 \%$ confluence. Chemical compounds to be analyzed were diluted in DMSO; cytotoxic activity was evaluated by adding twofold serial dilutions of the compound to be analyzed, starting at a $1600 \mu \mathrm{g} / \mathrm{mL}$ concentration; the plates were further incubated $(24 \mathrm{~h})$. For cytotoxic evaluation, alamar blue

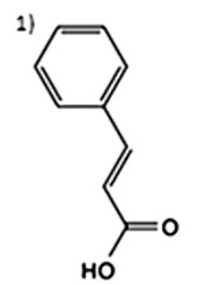

2)

6)<smiles>Cc1ccc(C(C)C)cc1</smiles><smiles>C=C1CC/C=C(/C)CC[C@@H]2C(C)C[C@H]1C2(C)C</smiles><smiles>CC1(C)[C@H]2CC[C@@]1(C)C(=O)C2</smiles>

3)<smiles>COc1ccc(C=O)cc1</smiles><smiles>Cc1ccc(C(C)C)cc1O</smiles><smiles>CC(C)=CCC[C@H](C)CCO</smiles>

12)<smiles>CC(C)c1ccc(C=O)cc1</smiles>

13)<smiles>C=CCc1ccc(OC)cc1</smiles>

16)<smiles>CC(C)=CCC/C(C)=C/CO</smiles>

18)
17)<smiles>C=C(C)C1CC=C(C)CC1</smiles>

22)<smiles>C/C=C/c1ccc(OC)cc1</smiles>

4)<smiles>CC1=CC[C@@H]2C[C@H]1C2(C)C</smiles><smiles>C=C(C)[C@H]1CC=C(C)C(=O)C1</smiles>

14)<smiles>C[C@H]1O[C@]2(C)CC[C@@H]1C2(C)C</smiles><smiles>C=C[C@@](C)(O)CCC=C(C)C</smiles>

23)

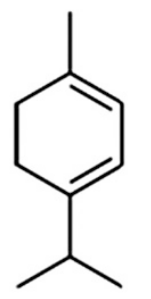

191<smiles>CC(C)[C@H]1CC[C@@H](C)C[C@H]1O</smiles>

24)<smiles>CC1=CCC(=C(C)C)CC1</smiles><smiles>CC1=CCC2C(C1)C2(C)C</smiles>

10)<smiles>O=C/C=C/c1ccccc1</smiles>

15)<smiles>C=CCc1ccc(O)c(OC)c1</smiles>

20)<smiles>C=CC(=C)CCC=C(C)C</smiles>

25)<smiles>Cc1ccc(C(C)C)c(O)c1</smiles>

Fig. 1 Chemical structures of terpenes and phenylpropanes evaluated against Mycobacterium tuberculosis and Mycobacterium bovis and studied by molecular modeling technique. 1) Cinnamic Acid; 2) Camphor, 3) p-Anisaldehyde; 4) $\beta$-pinene; 5) 3-Carene; 6) p-Cymene; 7) $\beta$-Cariophylene; 8) Carvacrol; 9) (+) Carvone; 10) Cinnamaldehyde; 11) $\beta$-Citronellol; 12) Cuminaldehyde: 13) Estragole; 14) Eucalyptol; 15) Eugenol; 16) Geraniol; 17) (+) Limonene; 18) Linalool; 19) Menthol; 20) Myrcene; 21) Sabinene; 22) t-Anethole; 23) a-Terpinene; 24) Terpinolene; 25) Thymol 
(Sigma, R7017) solution was added $(10 \% v / v)$ and after $3 \mathrm{~h}$, results were evaluated by determination of the change in color using a fluorimeter $(590 \mathrm{~nm})$. For negative control, cells were incubated with $500 \mu \mathrm{g} / \mathrm{mL}$ concentration of DMSO (Sigma, 472301), which was the highest concentration. Cytotoxic concentration $\left(\mathrm{CC}_{50}\right)$ was determined using probit non-linear regression.

\section{Chemical descriptors characterization}

Chemical structures of the compounds included in this work were analyzed with the Spartan 03 software [20] carrying out a conformational analysis of each molecule in gas phase using a mechanics force field SYBYL [21]. The minimum energy conformation was selected to obtain geometry optimization through a mechano-quantum calculation at level PM3 semi-empirical theory and numerical precision with minimal base [22]. Once the minimum energy geometries were obtained, the analytical frequency calculations were carried out for each stationary structure to verify if it was a minimum or a first order saddle point. Physicochemical, topological, constitutional, and charge descriptors were generated using the Dragon 5.0 program [23].

\section{Structure-antimycobacterial activity models}

With all the biological activities (MIC for mycobacteria) and the calculated theoretical descriptors obtained, a QSAR study was carried out by generating genetic algorithms using the Mobydigs Software [24]. The quality of the model was considered statistically satisfactory based on the determination coefficient $\left(R^{2}\right)$ value, the leaveone-out cross-validated variance $\left(\mathrm{Q}^{2}\right)$ and the $\mathrm{F}$ value of a given model. QSAR models were obtained using only structural descriptors in order to determine which structural arrangement and functional groups are important for the biological activity; in this case, for the antimycobacterial activity. QSAR models were also done based on all descriptors calculated from the molecular systems evaluated. Models were selected based on the four molecular properties that were identified as best related to the antimycobacterial activity.

\section{Molecular modeling and chemical reactivity analysis}

Molecular systems were recalculated using the Gaussian 09 program [25] for the calculation of quantum mechanical descriptors related to reactivity. Geometry optimizations and frequency calculations were done by density functional theory (DFT) in aqueous phase, using the functional B3LYP which is a hybrid Hartree-Fock density functional theory (HF-DFT) functional that combines Becke's three parameter exchange functional (B3) [26] and the correlation functional of Lee, Yang, and Parr (LYP) [27] in combination with the basis set 6-311G *.
Chemical reactivity descriptors: HOMO orbital and LUMO orbital energies; dipole moment, ionization potential, electron affinity, chemical potential, electronegativity, chemical hardness, chemical softness and aqueous solvation energy were obtained in aqueous phase from the energy calculations using Hartree-Fock (HF) with a 6-311G** basis set on optimized structures calculated with DFT:B3LYP/6-311**.* The HOMO (highest occupied molecular orbital) and LUMO (lowest unoccupied molecular orbital) frontier orbitals, as well as the Koopmans theorem [28] were applied for the calculations of the chemical reactivity descriptors. All the properties obtained in aqueous phase were calculated considering a polarized Condutor-continuum model (CPCM) [29].

\section{Statistical analysis}

Statistical analysis to reveal differences in antimicrobial activity of the chemical compounds analyzed was done by ANOVA test and differences within groups were done by Tukey test, with a $5 \%$ significance level. Statistical analysis was done using the statistical software Minitab 17 [Computer software State College, PA].

\section{Results \& Discussion}

In vitro potency of terpenes and phenylpropanes against M. tuberculosis and $M$. bovis

The major components of the essential oils were initially solubilized in pure ethanol, and the higher amount of the solvent was used as control to test for inhibitory effects, but no inhibitory effects were observed with the amount of solvent used. When considering MIC values of all compounds tested, a higher antimycobacterial activity was observed for M. tuberculosis strain as compared to M. bovis (average MIC for M. tuberculosis $\mathrm{H} 37 \mathrm{Rv}$ was $22.78 \mu \mathrm{g} / \mathrm{mL}$ and average MIC for M. bovis AN5 was $32.07 \mu \mathrm{g} / \mathrm{mL}$ ), and statistical analysis showed differences between the two strains. Thymol and carvacrol were the terpenes with higher antimycobacterial activity; thymol had MIC values of 0.78 and $2.02 \mu \mathrm{g} / \mathrm{mL}$ against strain of $M$. tuberculosis and M. bovis respectively. On the other hand, carvacrol presented MIC values of 2.02 and $5.20 \mu \mathrm{g} / \mathrm{mL}$ respectively for each mycobacteria tested. The antimycobacterial activity of thymol was grouped along with the activity of isoniazid and rifampicin by Tukey analysis (Table 1). Cinnamaldehyde and cinnamic acid were the most active phenylpropanes; cinnamic acid presented a MIC of 8.16 and $3.12 \mu \mathrm{g} / \mathrm{mL}$ for cinnamaldehyde; in both cases with the M. tuberculosis strain. In the case of M. bovis, cinnamic acid MIC was $7.29 \mu \mathrm{g} / \mathrm{mL}$ and MIC of cinnamaldehyde was $12.50 \mu \mathrm{g} / \mathrm{mL}$. Caryophyllene and $p$-cymene were the terpenes with lower antimycobacterial activity.

Citronellol, geraniol and myrcene, are acyclic monoterpenes with structural similarities and MIC results were 
Table 1 Antimycobacterial activity of terpenes and phenylpropanes against M. tuberculosis and M. bovis

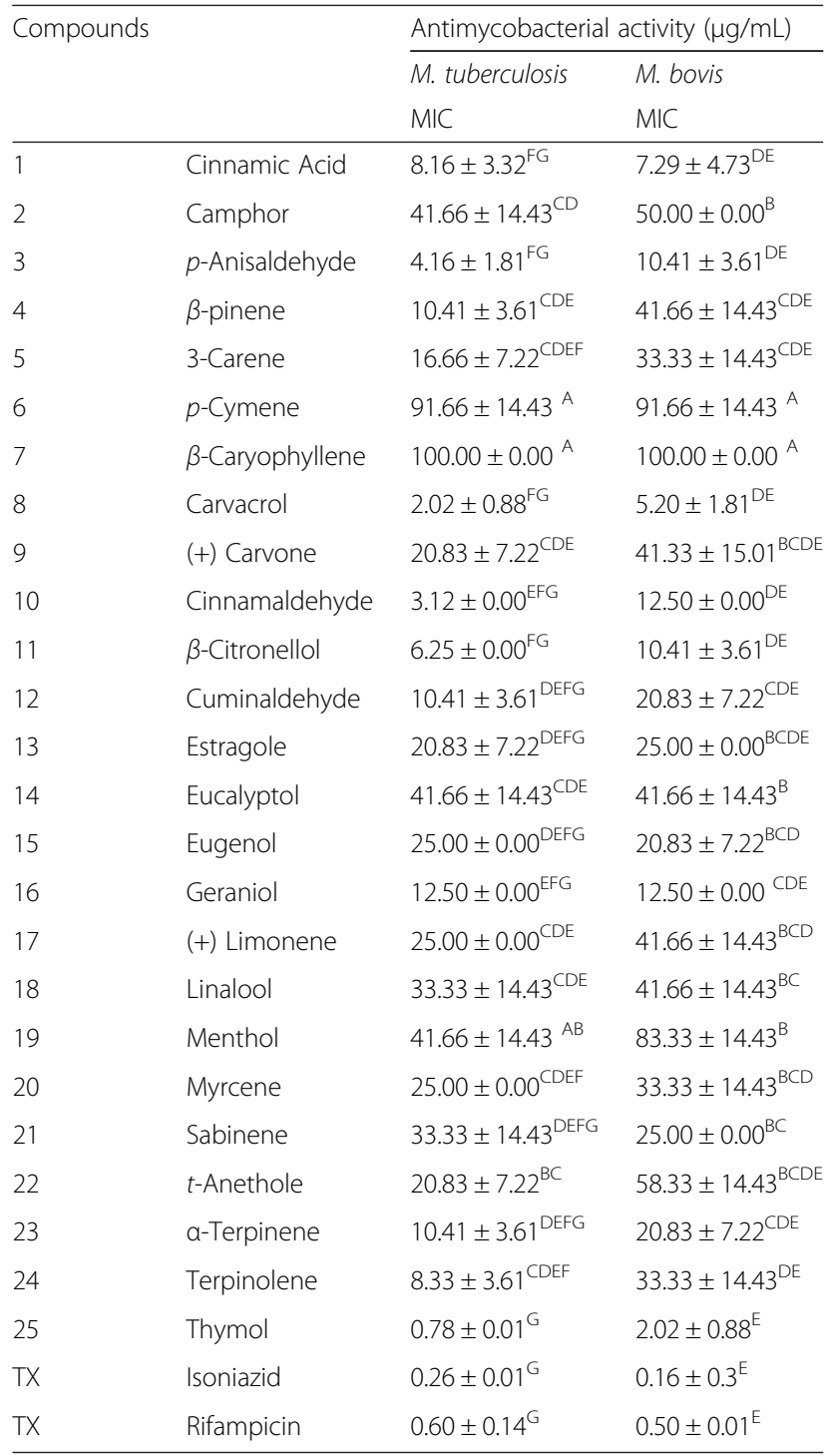

Values are the average and standard deviation of triplicate assays. Superscripts correspond to clusters by similarity analysis done by Tukey mean analysis

6.25, 12.5 and $25 \mu \mathrm{g} / \mathrm{mL}$ for $M$. tuberculosis respectively. Geranylgeraniol and geranylgeranyl acetate have been identified as potent and selective inhibitors against $M$. tuberculosis with a MIC of 1.56 and $3.13 \mu \mathrm{g} / \mathrm{mL}$ respectively [30]. Linalool is an acyclic monoterpene with a tertiary hydroxyl group and has a lower antimycobacterial activity as compared to geraniol and citronellol. Results indicate that the primary hydroxyl group confers increased activity to the open chain terpenes. The importance of the hydroxyl group is also evident in the model structure-antimycobacterial activity against $M$. bovis.

Antimycobacterial activity assays using the Alamar Blue technique against $M$. tuberculosis and $M$. bovis showed that thymol and carvacrol (major constituents of the oregano essential oil) as well as cinnamic acid and cinnamaldehyde (constituent of the cinnamon essential oil) have antimycobacterial activities of therapeutic importance. The efficiency of the antimycobacterial activity of thymol and carvacrol has been reported previously [31]; also, the biological activity against mycobacteria has been reported for the complete essential oil [32, 33]. Cinnamic acid has been used as a synergist with drugs traditionally used in tuberculosis treatment [34].

The deleterious effect on structure and function of microbial membrane and cell wall, has been generally used to explain the antimicrobial action of the essential oils and their components especially monoterpenoids. It has been shown that monoterpenes are able to interact with phospholipid membranes, functioning as interstitial impurities in the ordered structure of the lipid bilayer [35] as a result of their lipophilic character; it can then be described the preference of terpenes to the microbial membrane structures [36]. The effects of specific components of some essential oil on the permeability of the outer membrane of Gram-negative bacteria have been demonstrated, showing that the absorption of the monoterpene is also determined by the permeability of the outer envelope of the microorganism. This hypothesis demonstrates a potential use of terpenes and phenylpropanes as antimycobacterial agents, since the mycobacteria cell wall is highly lipophilic due to the presence of mycolic acids. The lipophilicity of the major components of essential oils allows them to interact easily with the mycobacterial cell wall, with the consequent changes on cell permeability and microbial death.

\section{Cytotoxic activity of terpenes on macrophage J774A cell line}

Carvacrol and thymol were analyzed to determine their cytotoxic activity, since both compounds demonstrated the higher antimycobacterial activity of all compunds tested. Due to its structural similarities, the cytotoxic activity of $p$-cymene and menthol were also evaluated, with the idea of being able to identify a structural relationship in the cytotoxic activity of these compounds. Results are shown in Table 2 and show a low cytotoxic activity of each compound as related to its antimicrobial activity. Thymol had a $\mathrm{CC}_{50}$ of $483.33 \mu \mathrm{g} / \mathrm{mL}$ while carvacrol eliminated $50 \%$ of the macrophages at a concentration of $900 \mu \mathrm{g} / \mathrm{mL}$. Menthol was the terpene with the lower cytotoxic activity. Although carvacrol and thymol presented cytotoxic activity, the CC50 concentration is much higher than the concentration needed for mycobacterial elimination (approximately 500 fold); the compounds can then, be considered as potential antimycobacterial agents. 
Table 2 Cytotoxic concentrations of p-Cymene, carvacrol, menthol and thymol solutions on $\mathbf{J 7 7 4}$ macrophages

\begin{tabular}{lll}
\hline Compounds & \multicolumn{2}{l}{ Cytotoxic activity $(\mu \mathrm{g} / \mathrm{mL})$} \\
\cline { 2 - 3 } & $\mathrm{CC}_{50}$ & $\mathrm{CC}_{90}$ \\
\hline p-Cymene & $1166.67 \pm 44.34$ & $2200.00 \pm 86.60$ \\
Carvacrol & $900.00 \pm 86.60$ & $1950.00 \pm 107.44$ \\
Menthol & $1450.00 \pm 180.28$ & $2600.00 \pm 304.14$ \\
Thymol & $483.33 \pm 28.87$ & $1133.33 \pm 115.47$ \\
\hline
\end{tabular}

Values are the average and standard deviation of three assays

\section{QSAR models for antimycobacterial activity}

The QSAR model for the H37Rv strain of $M$. tuberculosis that showed a statistical significance for structural properties included the following descriptors: number of total tertiary $\mathrm{C}\left(\mathrm{sp}^{3}\right)(\mathrm{nCt})$, number of terminal primary $\mathrm{C}\left(\mathrm{sp}^{2}\right) \quad(\mathrm{nR}=\mathrm{Cp})$, the number of phenolic groups $(\mathrm{nArOH})$ and an inverse relationship with the number of ketone groups (nRCO). The best model is expressed in Eq. 1 and it demonstrates the importance of the phenolic groups and $\pi$ bonds in the structures of major components of essential oils with antimycobacterial activity.

$$
\begin{aligned}
\log M I C & =0.1879(n C t)+0.03630(n R=C p) \\
& +1.1729(n A r O H)-1.1159(n R C O)-0.8750
\end{aligned}
$$

\begin{tabular}{llll}
\hline$n=25$ & $\mathrm{Q}^{2}=74.63$ & $\mathrm{R}^{2}=80.23$ & $\mathrm{~F}=14.2$
\end{tabular}

Results of QSAR models of chemical constituents of essential oils for $M$. bovis AN5 showed that the number of conjugated carbons ( $\mathrm{nCconj}$ ), the number of phenolic groups (nArOH), the number of hydroxyl groups $(\mathrm{OH})$ and the number of acceptor atoms of hydrogen bonds (nHAcc) were the most important structural descriptors in the activity. The best model is described in Eq. 2 and as with the H37Rv strain of $M$. tuberculosis, the model for $M$. bovis AN5 strain shows that the phenolic and hydroxyl groups are functional groups of biological importance.

$$
\begin{aligned}
\operatorname{LogMIC} & =0.09324(n C c o n j)+1.0900(n A r O H) \\
& +0.3395(n O H)+0.2349(n H A c c)-1.6318
\end{aligned}
$$

\begin{tabular}{lllll}
\hline$n=25$ & $\mathrm{Q}^{2}=79.09$ & $\mathrm{R}^{2}=82.11$ & $\mathrm{~F}=14.9$ & $\mathrm{~s}=0.186$ \\
\hline
\end{tabular}

Regarding molecular properties and antimycobacterial activity against $\mathrm{H} 37 \mathrm{Rv}$ strain of $M$. tuberculosis, the best model included the following predictors: partition coefficient Octanol/Water (MLogP), molar volume (MV), absolute total charge (Qtot) and electron affinity (A). The model is expressed in the Eq. 3.

$$
\begin{aligned}
\log M I C & =0.4824(M \log P)+0.0281(M V) \\
& -0.01775(Q t o t)-0.1889(A)+3.0240
\end{aligned}
$$

\begin{tabular}{lllll}
\hline$n=25$ & $\mathrm{Q}^{2}=81.25$ & $\mathrm{R}^{2}=91.69$ & $\mathrm{~F}=24.9$ & $\mathrm{~S}=0.106$
\end{tabular}

This model considers the Moriguchi octanol-water partition coefficient (MLogP) and molar volume (MV) descriptors as those with higher contribution to the antimycobacterial activity. A plot of the predicted activity versus experimental activity for molecules using a training set for models of M. tuberculosis is shown in Fig. 2. The statistics for other three QSAR models generated by analysis of genetic algorithms are included in Table 3.

Regarding molecular properties, the best QSAR model (Eq. 4) considers the full set of descriptors, being the four with higher biological significance the unipolarity (UNIP), the hydrophilicity (Hy), the molar volume (MV) and the dipole moment $(\mathrm{m})$.

$$
\begin{aligned}
\operatorname{LogMIC} & =0.07613(\mathrm{UNIP})-0.9780(H y) \\
& +0.2692(\mathrm{MV})-0.2497(m)+1.0095
\end{aligned}
$$

\begin{tabular}{lllll}
\hline$n=25$ & $\mathrm{Q}^{2}=44.67$ & $\mathrm{R}^{2}=78.49$ & $\mathrm{~F}=10.9$ & $\mathrm{~s}=0.201$ \\
\hline
\end{tabular}

A plot of the predicted activity versus experimental activity for molecules using a training set for $M$. bovis models is shown in Fig. 3. The statistics of other three QSAR models generated by analysis of genetic algorithms are shown in Table 4.

Studies relating molecular properties of compounds and their antimycobacterial activity strengthen this hypothesis, since the descriptor octanol/water (MlogP) shows the higher contribution to the activity against $M$. tuberculosis in the QSAR model. For M. bovis QSAR model, the hydrophilicity (Hy) property exhibits the most important contribution, but the relationship is inverse with antimycobacterial activity.

The Molar Volume (MV) descriptor has been used to suggest a possible mechanism of action of the antimicrobial compounds in the solute-transfer process across biological 

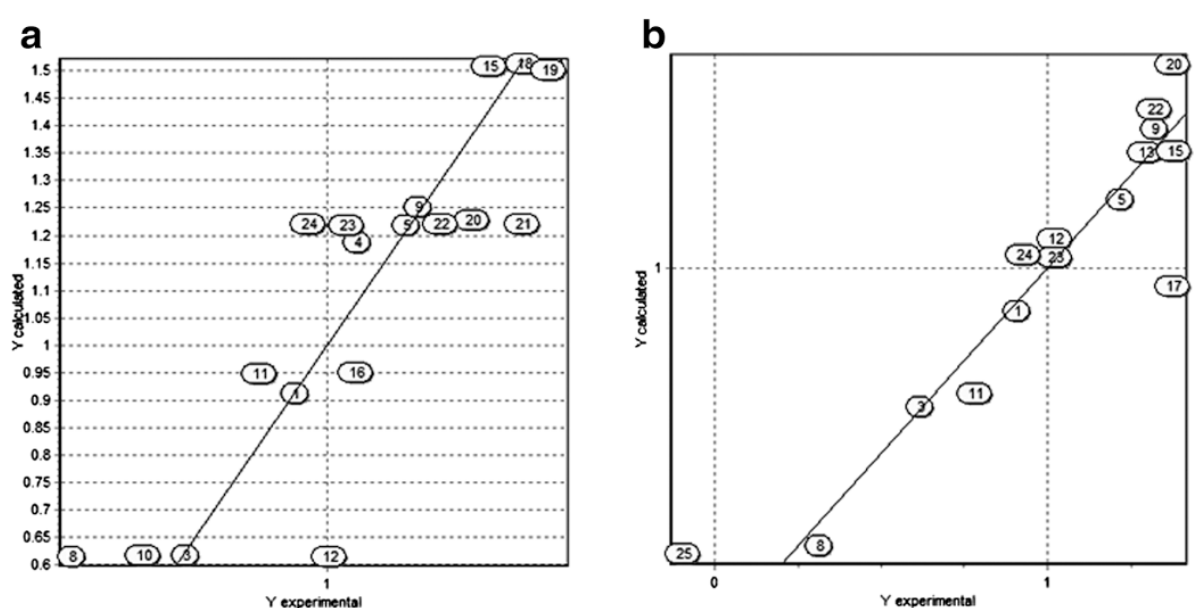

Fig. 2 Predicted versus experimental antimycobacterial activity against M. tuberculosis for molecules in the training set used. a Structural descriptors model. b Molecular descriptors model

membranes [37]. This descriptor is included in both models based on molecular properties, which suggest that the mechanism of action of terpenes and phenylpropanes might be related to an effect on the mycobacterial cell wall. QSAR studies of molecular structure proposes that the number of conjugated carbons ( $\mathrm{nCconj)}$ ) as well as the number of terminal primary $\mathrm{C}\left(\mathrm{sp}^{2}\right)(\mathrm{nR}=\mathrm{Cp})$ are important structural descriptors for the antimycobacterial activity, which can be related to the biological activity of aldehydes.

Regarding QSAR models for molecular properties and antimycobacterial activity, the models indicate that the partition coefficient octanol/water (MlogP) and molar volume (MV) descriptors are the major contributors for the biological activity. The chemical reactivity theoretical descriptors such as dipole moment $(\mathrm{m})$ and electron affinity (A), were considered by the model as descriptors in inverse relation to the biological activity. The absolute total charge (Qtot) (a charge descriptor) was also considered in inverse relation to the biological activity.

Even though results of QSAR models suggests that the chemical compounds identified as major constituents of essential oils have as target structure of the antimicrobial

Table 3 A summary of the statistics QSAR models for activity against M. tuberculosis

\begin{tabular}{|c|c|c|c|c|c|c|c|}
\hline \multirow[t]{2}{*}{ Parameter } & \multicolumn{3}{|c|}{ Structure-activity relationship } & \multirow[t]{2}{*}{ Parameter } & \multicolumn{3}{|c|}{ Property-Activity Relationship } \\
\hline & Model 2 & Model 3 & Model 4 & & Model 2 & Model 3 & Model 4 \\
\hline$n$ & 25 & 25 & 25 & $\mathrm{n}$ & 25 & 25 & 25 \\
\hline$Q^{2}$ & 70.50 & 69.25 & 67.25 & $Q^{2}$ & 81.25 & 79.13 & 78.16 \\
\hline$R^{2}$ & 77.83 & 77.54 & 77.54 & $R^{2}$ & 87.69 & 87.08 & 87.08 \\
\hline $\mathrm{F}$ & 12.3 & 12.1 & 12.1 & $\mathrm{~F}$ & 24.9 & 23.6 & 23.6 \\
\hline s & 0.260 & 0.261 & 0.261 & s & 0.160 & 0.164 & 0.164 \\
\hline Contributions (\%) & & & & Contributions (\%) & & & \\
\hline nCrt & 0.1678 & - & - & MlogP & 0.4824 & 0.4559 & 0.4559 \\
\hline $\mathrm{nCq}$ & - & 0.3001 & - & MV & 0.0281 & 0.0283 & 0.0283 \\
\hline $\mathrm{nCrq}$ & - & - & 0.3001 & $E_{\text {LUMO }}$ & 0.1889 & - & 0.1877 \\
\hline$n R=C p$ & 0.3635 & 0.3657 & 0.3657 & Se & - & -0.1144 & -0.1144 \\
\hline $\mathrm{nArOH}$ & 1.0495 & 1.0570 & 1.0570 & Qtot & -0.0175 & - & - \\
\hline $\mathrm{nRCO}$ & -1.1609 & -1.0026 & -1.0026 & A & - & -0.1877 & - \\
\hline Intercept & -0.9395 & -0.9470 & -0.9470 & Intercept & 3.0240 & 2.2534 & 2.2534 \\
\hline
\end{tabular}

$n$ Number of systems evaluated, $Q^{2}$ The square of the coefficient of cross-validation, $R^{2}$ The square of the correlation coefficient, $s$ standard deviation, $F$ Fisher statistic

Physicochemical, structural, topological and constitutional descriptors: $n C r t$ number of ring tertiary $C\left(\mathrm{sp}^{3}\right)$, $n C q$ number of total quaternary $C\left(\mathrm{sp}^{3}\right)$, $n C r q$ number of ring quaternary $C(\mathrm{sp} 3), n R=C p$ number of terminal primary $C\left(\mathrm{sp}^{2}\right), n A r O H$ number of phenolic groups, $n R C O$ number of ketone groups, $E_{L U M O}$ Energy LUMO orbital, MlogP Moriguchi octanol-water partition coeff., MV Molar Volume, Se sum of atomic Sanderson electronegativities (scaled on Carbon atom), Qtot total absolute charge), $A$ Electron Affinity 

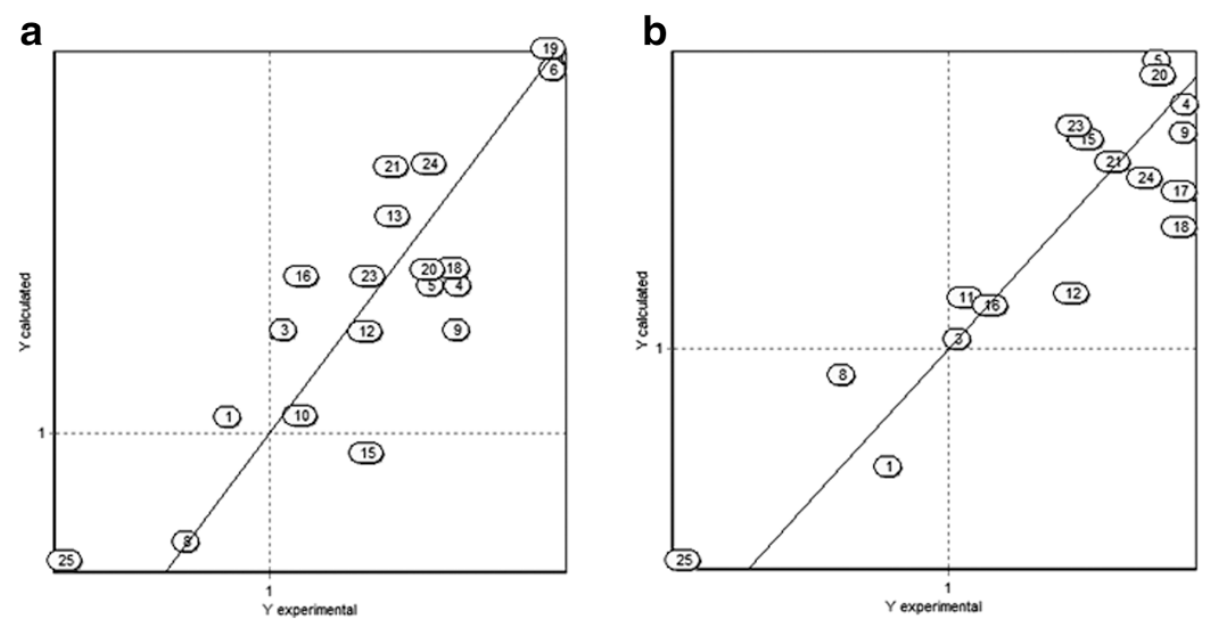

Fig. 3 Predicted versus experimental antimycobacterial activity against M. bovis for molecules in the training set based. a Structural descriptors model. b Molecular descriptors model

activity the microbial cell wall, it is important to also consider other biological targets. It had been reported that thymol and carvacrol molecules have affinity for the chorismate mutase enzyme that is part of the shikimate pathway and is a key enzyme located at the branching point of the pathway [31]. Because of the importance of shikimic acid pathway for the synthesis of aromatic aminoacids, which is only found in Eubacteria and Protista organisms, it is important to be considered as a prime target for the development of new antimicrobial agents. Under this premise, it was decided to focus the study of chemical reactivity and cytotoxicity of thymol, carvacrol, $p$-cymene and menthol, compounds which have structural similarity and have different antimycobacterial activity.

\section{Chemical reactivity analysis of $\mathrm{p}$-Cymene, menthol, carvacrol and thymol}

A Chemical reactivity analysis was done for the compounds with MIC values of therapeutic importance (thymol and caravacrol), but $p$-cymene and menthol were included considering their structural similarity with the first two compounds. The Optimized

Table 4 A summary of the statistics of the QSAR models for activity against M. bovis

\begin{tabular}{|c|c|c|c|c|c|c|c|}
\hline \multirow[t]{2}{*}{ Parameter } & \multicolumn{3}{|c|}{ Structure-activity relationship } & \multirow[t]{2}{*}{ Parameter } & \multicolumn{3}{|c|}{ Property-Activity Relationship } \\
\hline & Model 2 & Model 3 & Model 4 & & Model 2 & Model 3 & Model 4 \\
\hline$n$ & 25 & 25 & 25 & $\mathrm{n}$ & 25 & 25 & 25 \\
\hline$Q^{2}$ & 76.94 & 75.12 & 72.31 & $Q^{2}$ & 70.25 & 70.64 & 69.51 \\
\hline$R^{2}$ & 79.89 & 79.10 & 77.06 & $R^{2}$ & 76.89 & 74.43 & 72.54 \\
\hline $\mathrm{F}$ & 12.7 & 12.3 & 10.9 & $\mathrm{~F}$ & 10.0 & 8.7 & 7.9 \\
\hline s & 0.198 & 0.201 & 0.210 & s & 0.209 & 0.219 & 0.227 \\
\hline Contributions (\%) & & & & Contributions (\%) & & & \\
\hline$n C p$ & -0.1381 & - & -0.0921 & UNIP & 0.1095 & 0.1052 & 0.0609 \\
\hline nCconj & 0.0893 & 0.0557 & 0.0611 & Hy & -1.3558 & -1.3505 & -0.9442 \\
\hline $\mathrm{nArOH}$ & 1.3088 & 1.0765 & 0.9820 & $A \log P$ & 0.4974 & - & - \\
\hline $\mathrm{nOH}$ & 0.6965 & - & - & $A \log P^{2}$ & - & 0.0831 & - \\
\hline $\mathrm{nR}=\mathrm{Ct}$ & - & 0.0968 & - & $\mathrm{E}_{\text {Hомо }}$ & - & - & -0.2230 \\
\hline HACC & - & 0.3346 & 0.2500 & $\mathrm{~m}$ & -0.2835 & -0.2653 & -0.1215 \\
\hline Intercept & - 1.2011 & -1.7189 & -1.5389 & Intercept & 0.0065 & 0.6590 & 2.3500 \\
\hline
\end{tabular}

$n$ Number of systems evaluated, $Q^{2}$ The square of the coefficient of cross-validation, $R^{2}$ The square of the correlation coefficient, $s$ standard deviation, $F$ Fisher statistic

Physicochemical, structural, topological and constitutional descriptors: $n C p$ Number of terminal primary $C\left(\mathrm{sp}^{3}\right), n C c o n j$ Number of non-aromatic conjugated $C$ $\left(\mathrm{sp}^{2}\right), n A r O H$ Number of fenólico groups, $n O H$ Number of hydroxyl groups, $n R=C t$ Number of aliphatic tertiary $C\left(\mathrm{sp}^{2}\right)$, HAcc Number of acceptor atoms for $\mathrm{H}$-bonds $(\mathrm{N}, \mathrm{O}, \mathrm{F})$, UNIP Unipolarity, AlogP Ghose-Crippen octanol-water partition coeff., Alog $P^{2}$ Squared Ghose-Crippen octanol-water partition coeff., $E_{\text {Hомо }}$ Energy of the HOMO orbital, $m$ Dipole moment 
Table 5 Theoretical descriptors of chemical reactivity for terpenes calculated by Hartree-Fock (HF) with a 6-311G**

\begin{tabular}{llllllllllll}
\hline Molecule & $\begin{array}{l}\mathrm{E}_{\text {Hомо }} \\
(\mathrm{eV})\end{array}$ & $\begin{array}{l}\mathrm{E}_{\text {LUMO }} \\
(\mathrm{eV})\end{array}$ & $\begin{array}{l}\mathrm{GapE} \\
(\mathrm{eV})\end{array}$ & $\begin{array}{l}\mathrm{m} \\
(\text { Debye })\end{array}$ & $\begin{array}{l}\mathrm{l} \\
(\mathrm{eV})\end{array}$ & $\begin{array}{l}\mathrm{A} \\
(\mathrm{eV})\end{array}$ & $\begin{array}{l}\mu \\
(\mathrm{eV})\end{array}$ & $\begin{array}{l}\mathrm{X} \\
(\mathrm{eV})\end{array}$ & $\begin{array}{l}\eta \\
(\mathrm{eV})\end{array}$ & $\begin{array}{l}\mathrm{S} \\
(\mathrm{eV})\end{array}$ & $\begin{array}{l}\Delta \mathrm{G}_{\text {solv }} \\
(\mathrm{kcal} / \mathrm{mol})\end{array}$ \\
\hline p-Cymene & -8.4628 & 3.8068 & 4.6560 & 0.0890 & 8.4628 & -3.8068 & 2.3280 & -2.3280 & 6.1348 & 0.1630 & 7.71 \\
Carvacrol & -8.2859 & 3.9429 & 4.3431 & 1.9475 & 8.2859 & -3.9429 & 2.1715 & -2.1715 & 6.1144 & 0.1635 & 1.11 \\
Menthol & -10.8438 & 5.7769 & 5.0669 & 2.4083 & 10.8438 & -5.7769 & 2.5335 & -2.5335 & 8.3104 & 0.1203 & 3.63 \\
Thymol & -8.3104 & 3.8640 & 4.4465 & 1.8865 & 8.3104 & -3.8640 & 2.2232 & -2.2232 & 6.0872 & 0.1643 & 1.67 \\
\hline
\end{tabular}

$E_{\text {номо }}$ Energy of the HOMO orbital, $E_{L U M O}$ Energy LUMO orbital, $m$ Dipole moment, GapE $\mathrm{E}_{\text {LUMо }}$ - $\mathrm{E}_{\text {номо }}$ Gap energy, I lonization potential, $A$ Electron Affinity, $\mu$ Chemical potential $X$ Electronegativity, $\eta=$ Chemical hardness, $S$ Chemical softness, $\omega$ Electrophilicity, $\Delta G_{\text {solv }}$ Aqueous solvation energy

structures and the contour plots for the HOMO and LUMO molecular orbitals are shown in Fig. 4.

The HOMO and LUMO molecular orbitals of $p$-cymene, carvacrol and thymol are located on the benzene rings, in the case of thymol and carvacrol molecules the HOMO orbital also includes oxygen atoms. The location of the HOMO and LUMO orbitals of menthol molecule have less symmetry, which could be associated with the absence of $\pi$ bonds in the structure. Chemical reactivity analysis revealed that menthol shows the lowest energy calculated for the HOMO orbital of the four compounds analyzed, and presents the largest dipole moment and chemical hardness. On the other hand, $p$-cymene has the highest energy for the LUMO orbital and the lowest value for the dipole moment. Thymol and carvacrol showed intermediate values in most chemical reactivity descriptors (Table 5).

The most active compounds for both strains have phenolic groups in their chemical structure. There are several reports on the importance of the hydroxyl group present in thymol and carvacrol, and the authors describe this functional group as key for their antimicrobial activity [8]. This observation is supported by the QSAR models reported here, which consider the phenolic group (nArOH) as the structural descriptor of biological importance. The importance of the phenolic group is also observed by comparing the biological activities of thymol and menthol, since the difference is precisely the aromatic ring conformation. Menthol and thymol have

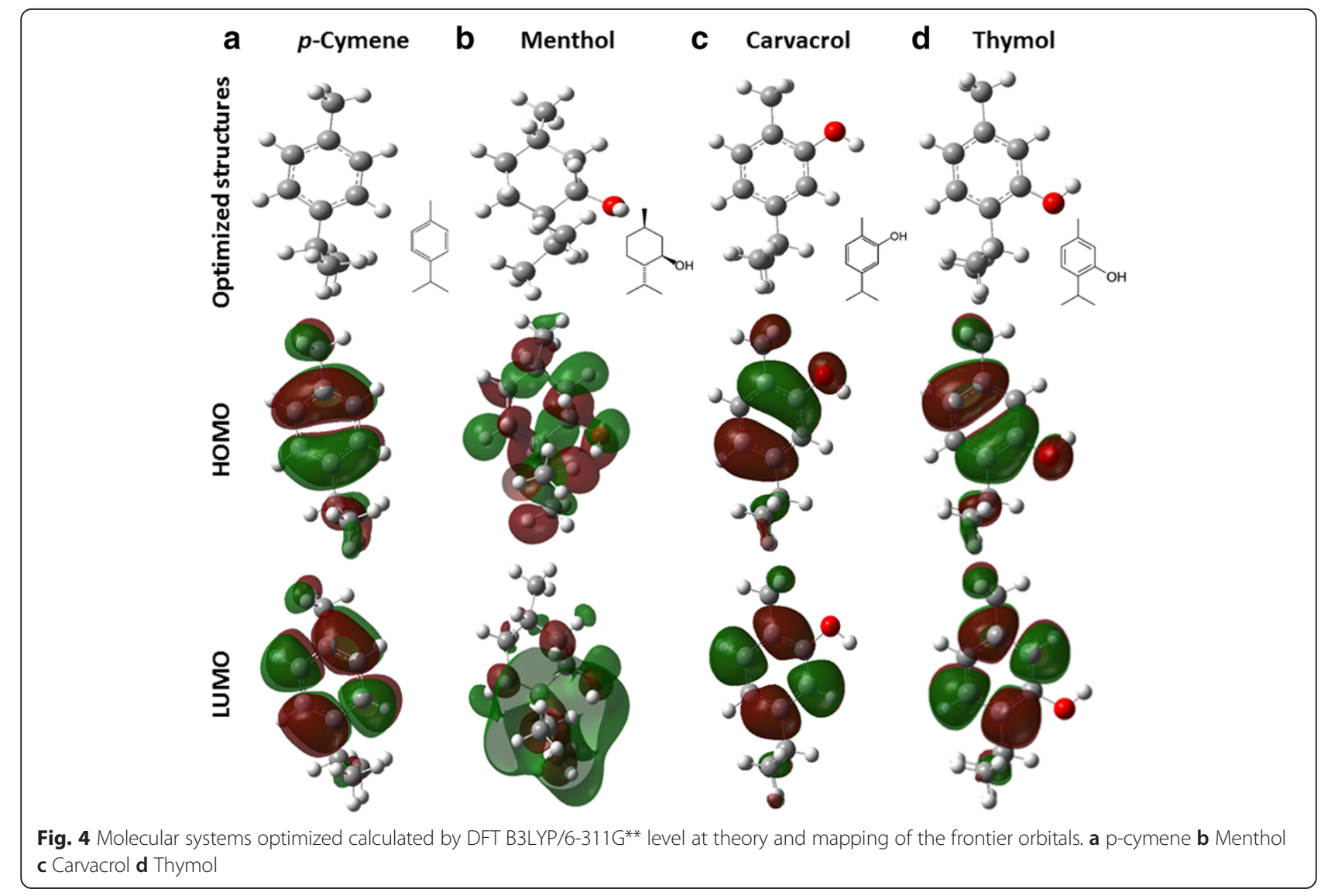


the hydroxyl group in the same position but the menthol had lower antimicrobial activity, and also lower cytotoxic activity. Furthermore, the difference in activities between thymol and carvacrol resides in the hydroxyl group position relative to the larger aliphatic chain. Thymol has the hydroxyl group in meta position while carvacrol contains the hydroxyl group in the ortho position and the later has lower antimycobacterial and cytotoxic activity. On the contrary, Alokam et al. [26] reported an increased activity in carvacrol as compared to thymol. The elimination of the substituents of the aromatic ring in carvacrol has been shown to reduces the antimicrobial activity of the resulting compound against $S$. aureus; even when the hydroxyl group is replaced by an amino group, the activity is lost [38]. Since the elimination of the organic groups does not affect hydrophobicity, spatial structure, and solubility of the resulting compound as compared to carvacrol, it can be concluded that the hydroxyl group confers a special chemical features that add to the antimicrobial mode of action of carvacrol.

A large number of useful molecular descriptors, related to the physical properties and chemical reactivity of molecules, can be derived from the information available from molecular orbitals. The energies of the highest occupied molecular orbital and the lowest unoccupied molecular orbital, $\mathrm{E}_{\mathrm{HOMO}}$ and $\mathrm{E}_{\mathrm{LUMO}}$ respectively belong to the most popular quantum mechanical descriptors used. The HOMO orbital is used as an indicator of the highest electron density area, so that these zones exhibit a favorable region to be attacked by electrophiles, while a reactive or nucleophilic compound will be attracted to areas with lower electron density indicated for LUMO orbital.

The HOMO orbital is mainly located on the benzene groups (Fig. 4) but in thymol and carvacrol, this orbital is positioned above the phenolic group. The Menthol molecule presents a less symmetrical distribution of HOMO orbital and shows the lowest energy of this orbital $\left(\mathrm{E}_{\mathrm{HOMO}}\right)$; of the four compounds analyzed, menthol was the system with highest chemical hardness ( $\eta$ ). Furthermore, menthol has a higher dipole moment $(\mathrm{m})$ and ionization potential (I). Thymol and carvacrol were the compounds with lower free energy of solvation. Cymene has the smaller dipole moment $(\mathrm{m})$ and the higher solvation free energy $\left(\Delta G_{\text {solv }}\right)$, and is therefore, the less water-soluble compound. These results demonstrate that the lipophilicity alone is not the responsible for the antimycobacterial activity, but this activity is also linked to the electronic characteristics of the phenolic group.

\section{Conclusion}

The antimycobacterial activity of terpenes and phenylpropanes that are present in diverse essential oils was analyzed by MIC for two mycobacterial strains. Molecules with higher antimycobacterial activity showed low cytotoxicity for macrophages and are candidates for further testing in in vivo models. The description of the molecular properties and the structural characteristics responsible for antimycobacterial activity of the tested compounds, were used for the development of mathematical models of quantitative structure-activity relationship (QSAR). The identification of molecular and structural descriptors provide insight into the mechanisms of action of the active molecules; the information provided can be used for the design of new chemical structures, that could be synthetized as potential new antimycobacterial agents.

\section{Competing interests}

The authors declare that they have no competing interests.

\section{Authors' contribution}

SAO carried out the biological analysis, worked on the theoretical description of the molecules and QSAR models and drafted the manuscript, GVNM participated in the design of the study, performed statistical analysis and worked on the manuscript, LEST participated on the cytotoxic activity of the most antimicrobial molecules, BESR participated on the biological activity of the molecules and drafting the manuscript, MVG participated on the development and analysis of QSAR models, LMRV worked on the development of the theoretical descriptors and the analysis of QSAR molecules and BERC conceived the study and participated in its design and coordination. All authors read and approved the final manuscript.

\section{Acknowledgments}

SAO received and scholarship from CONACYT for his graduate studies.

\section{Author details}

${ }^{1}$ Facultad de Ciencias Químicas, Universidad Autónoma de Chihuahua, Circuito Universitario S/N. Campus Universitario II, Chihuahua 31125 Chih., México. ${ }^{2}$ Escuela Nacional de Ciencias Biológicas, Instituto Politécnico Nacional. Prolongación de Carpio y Plan de Ayala S/N, Col. Santo Tomas 11340, México, DF, México. ${ }^{3}$ Asociación de Jubilados de la Universidad de Guanajuato, Guanajuato, Gto., México.

Received: 15 April 2015 Accepted: 11 September 2015

Published online: 23 September 2015

\section{References}

1. Global Tuberculosis Control 2014: World Health Organization. Available from: http://www.who.int/tb/publications/global_report/en/; April 14 2015.

2. World Health Organization. Multidrug and extensively drug resistant TB (M) XDR-TB) Global report on surveillance and response. Geneva: World Health Organization; 2010.

3. Zheng $Y$, Jiang $X$, Gao F, Song J, Sun J, Wang $L$, et al. Identification of plant-derived natural products as potential inhibitors of the Mycobacterium tuberculosis proteasome. BMC Complement Altern Med. 2014;14(1):400.

4. Robles-Zepeda RE, Coronado-Aceves EW, Velázquez-Contreras CA, Ruiz-Bustos E, Navarro-Navarro M, Garibay-Escobar A. In vitro anti-mycobacterial activity of nine medicinal plants used by ethnic groups in Sonora, Mexico. BMC Complement Altern Med. 2013;13(1):329

5. Canales M, Hernández T, Caballero J, Vivar A, Avila G, Duran A, et al. Informant consensus factor and antibacterial activity of the medicinal plants used by the people of San Rafael Coxcatlán, Puebla, México. J Ethnopharmacol. 2005;97(3):429-39.

6. Burt SA, Reinders RD. Antibacterial activity of selected plant essential oils against Escherichia coli O157: H7. Lett Appl Microbiol. 2003;36(3):162-7.

7. Kalemba D, Kunicka A. Antibacterial and antifungal properties of essential oils. Curr Med Chem. 2003;10(10):813-29.

8. Koroch AR, Juliani HR, Zygadlo JA. Bioactivity of essential oils and their components. In: Flavours and fragrances. Berlin Heidelberg: Springer; 2007. p. $87-115$. 
9. Dorman HJD, Deans SG. Antimicrobial agents from plants: antibacterial activity of plant volatile oils. J Appl Microbiol. 2000;88(2):308-16.

10. Rajab MS, Cantrell CL, Franzblau SG, Fischer NH. Antimycobacterial activity of (E)-phytol and derivatives. Planta Med. 1998;64(01):2-4

11. Newton SM, Lau C, Wright CW. A review of antimycobacterial natural products. Phytother Res. 2000;14(5):303-22.

12. Cantrell CL, Franzvlau SG, Fischer NH. Antimycobacterial Plant Terpenoids. Planta Med. 2001;67(8):685-94.

13. Poroikov W, Filimonov DA, Ihlenfeldt WD, Gloriozova TA, Lagunin AA, Borodina W, et al. PASS biological activity spectrum predictions in the enhanced open $\mathrm{NCl}$ database browser. J Chem Inf Comput Sci. 2003:43(1):228-36.

14. Geronikaki AA, Dearden JC, Filimonov D, Galaeva I, Garibova TL, Gloriozova $T$, et al. Design of new cognition enhancers: from computer prediction to synthesis and biological evaluation. J Med Chem. 2004;47(11):2870-6.

15. Subramaniam R, Rao G. 2D QSAR studies of some novel quinazolinone derivatives as antitubercular agents. J Comput Methods Mol Des. 2011;3:69-82.

16. Hernández-Ochoa L, Macias-Castañeda CA, Nevárez-Moorillón GV, Salas-Muñoz E, Sandoval-Salas F. Antimicrobial activity of chitosan-based films including spices essential oils and functional extracts. CyTA J Food. 2012;10(2):85-91.

17. Andrade-Ochoa S, Chacón-Vargas KF, Nevárez-Moorillón GV, Rivera-Chavira BE, Hernández-Ochoa LR. Evaluation of antimycobacterium activity of the essential oils of cumin (Cuminum cyminum), clove (Eugenia caryophyllata), cinnamon (Cinnamomum verum), laurel (Laurus nobilis) and anise (Pimpinella anisum) against Mycobacterium tuberculosis. Adv in Biol Chem. 2013;3:480-4.

18. Kumar K, Awasthi D, Lee SY, Zanardi I, Ruzsicska B, Knudson S, et al. Novel trisubstituted benzimidazoles, targeting Mtb FtsZ, as a new class of antitubercular agents. J Med Chem. 2010;54(1):374-81.

19. Collins L, Franzblau SG. Microplate alamar blue assay versus BACTEC 460 system for high-throughput screening of compounds against Mycobacterium tuberculosis and Mycobacterium avium. Antimicrob Agents Chemother. 1997;41(5):1004-9.

20. Deppmeier BJ et al. Spartan '08, build 132. Invine, CA Wavefunction Inc; 2009.

21. Mayo SL, Olafson BD, Goddard WA. DREIDING: a generic force field for molecular simulations. J Phys Chem. 1990;94(26):8897-909.

22. Stewart JJ. Optimization of parameters for semiempirical methods 1. Method. J Comput Chem. 1989;10(2):209-20.

23. Talete SRL. Dragon for Windows (software for Molecular Descriptor Calculations) Version 5.4, http://www.talete.mi.it/ 2006.

24. Todeschini R, Consonni V, Mauri A, Pavan M. MobyDigs: software for regression and classification models by genetic algorithms. Nature-inspired Methods in Chemometrics: Genetic Algorithms and Artificial Neural Networks. (Leardi R., Ed.), 2003. P. 141-167.

25. Frisch MJ et al. Gaussian 09, Revision D.01 ed. Wallingford, CT: Gaussian, Inc; 2009.

26. Becke AD. Density-functional thermochemistry III. The role of exact exchange. J Chem Phys. 1993;98(7):5648-52

27. Lee C, Yang W, Parr RG. Development of the Colle-Salvetti correlation energy formula into a functional of the electron density. Phys Rev B. 1988; $37: 785$

28. Koopmans T. Über die zuordnungwellenfunktionen von und zu den eigenwerteneinzelnen Elektronenátomoseines. Physica. 1934;1 (1):104-13.

29. Takano Y, Houk N. Benchmarking the conductor-like polarizable continuum model (CPCM) for aqueous solvation free energies of neutral and ionic organic molecules. J Chem Theory Comput. 2005;1 (1):70-7.

30. Vik A, James A, Gundersen LL. Screening of Terpenes and Derivatives for Antimycobacterial Activity; Identification of Geranylgeraniol and Geranylgeranyl Acetate as Potent Inhibitors of EM EMTYPE. Plan med. 2007;73(13):1410-2.

31. Alokam R, Jeankumar VU, Sridevi JP, Matikonda SS, Peddi S, Alvala M, et al. Identification and structure-activity relationship study of carvacrol derivatives as Mycobacterium tuberculosis chorismate mutase inhibitors. Enzyme Inhib Med Chem. 2013;29(4):1-8.

32. Jimenez-Arellanes A, Martinez R, García R, León-Díaz R, Luna-Herrera J, Molina-Salinas $G$, et al. Thymus vulgaris as a potencial source of antituberculous compounds. Pharmacol Online. 2006;3:569-74.

33. Siddiqui BS, Bhatti HA, Begum S, Perwaiz S. Evaluation of the antimycobacterium activity of the constituents from Ocimum basilicum against Mycobacterium tuberculosis. J Ethnopharmacol. 2012;144(1):220-2.
34. Rastogi N, Goh KS, Horgen L, Barrow WW. Synergistic activities of antituberculous drugs with cerulenin and trans-cinnamic acid against Mycobacterium tuberculosis. FEMS Immunol Med Microbiol. 1998:21(2):149-57.

35. Trombetta D, Castelli F, Sarpietro MG, Venuti V, Cristani M, Daniele C, et al. Mechanisms of Antibacterial Action of Three Monoterpenes. Antimicrob Agents Chemother. 2005;49(6):2474-8.

36. Sikkema J, de Bont JAM, Poolman B. Mechanisms of membrane toxicity of hydrocarbons. Microbiol Rev. 1995;59:201-22.

37. Martínez F, Gómez A. Estimation of the solubility of sulfonamides in aqueous media from partition coefficients and entropies of fusion. Phys Chem Liq. 2002;40(4):411-20.

38. Veldhuizen EJ, Tjeerdsma-van Bokhoven JL, Zweijtzer C, Burt SA, Haagsman HP. Structural requirements for the antimicrobial activity of carvacrol. J Agric Food Chem. 2006;54(5):1874-9.

\section{Submit your next manuscript to BioMed Central and take full advantage of:}

- Convenient online submission

- Thorough peer review

- No space constraints or color figure charges

- Immediate publication on acceptance

- Inclusion in PubMed, CAS, Scopus and Google Scholar

- Research which is freely available for redistribution

Submit your manuscript at www.biomedcentral.com/submit 